\title{
Factors predicting mortality in a total population sample of the elderly
}

\author{
A JOHN CAMPBELL, ${ }^{1}$ C DIEP, ${ }^{2} \mathrm{~J}^{\mathrm{REINKEN},{ }^{2} \text { AND L McCOSH }}$
}

From the Department of Medicine, ${ }^{1}$ Medical School, University of Otago, Dunedin; Management Services and Research Unit, ${ }^{2}$ Wellington; and Gisborne, ${ }^{3}$ New Zealand

SUMMARY Between 1977 and 1979 an age stratified sample of people 65 years and over living in the community and in institutions in Gisborne, New Zealand was assessed medically and socially. This sample was followed and reviewed in 1982. At follow up 308 subjects were seen, 227 had died, and 24 had left the area. Factors predicting mortality were assessed. Using a log rank test, factors predicting mortality included age, impaired mental function, functional disability, urinary incontinence, prescribed drugs, pulse pressure, erythrocyte sedimentation rate (ESR), systolic pressure, cardiovascular drugs, and falls. However, a number of these factors increased in prevalence with age. Using a Cox's regression analysis for factors predicting mortality after controlling for age, the following were found to be significant predictors: impaired mental function; functional disability; urinary incontinence; prescribed drugs, ESR and falls. A proportional hazards general linear model showed that the major predictors of mortality in old age were markers of established disease.

The death of an old person is commonly due to a combination of diseases occurring when age has impaired the body's ability to compensate for the effect of illness. A number of different causal factors may have contributed to the development of each disease. Studies to determine factors predicting mortality in the elderly are therefore unlikely to identify a single factor, the treatment of which would increase life expectancy. Such studies may, however, increase the understanding of the relation of ageing and disease processes causing morbidity and mortality in the elderly. Studies may also indicate that certain risk factors for death in young people are no longer important predictors in the elderly. This would have important implications in the investigation and treatment of these conditions. Studies may enable identification of an at risk group of elderly people for whom health care services would be of value. Information obtained will enable better planning of health care provision.

The majority of studies investigating factors predicting mortality in old people have examined a selected population such as those in institutions ${ }^{12}$ or receiving particular benefits, ${ }^{3}$ or have investigated certain specific variables only. ${ }^{4-6}$ There have been few studies of randomly selected community samples, and each has investigated different variables. $^{7-9}$
We have investigated factors predicting mortality in a prospective study of a randomly selected sample of elderly people living in both the community and in institutional care.

\section{Sample and method}

Names, ages, and addresses of all people 65 years and over who lived in Gisborne, New Zealand were obtained from a sample frame estimated to represent $97 \%$ of the elderly in the area. ${ }^{10}$ The sample frame included all elderly people living in the area, whether they lived in the community or in institutions. From this a randomly selected sample stratified by age was obtained. The sample included all those aged 80 years or more, a 1 in 6 sample of those 75-79 years, and a 1 in 20 sample of those aged 65-74 years. Subjects were assessed initially during 1978 and 1979. The final follow up examination was performed between October 1982 and February 1983. The minimum period of follow up was 42 months. The age of the subject was taken as the age at which he or she was first seen. The total number of people approached was 589 . Thirty refused to participate so the overall response rate was $94.9 \%$. Subjects were seen in their usual living situation. The nurse investigator carried out the initial interview 
and gathered personal information and details of family and professional support and functional ability. The medical investigator then saw each subject in his or her own home. The eye examination was carried out in the hospital eye clinic. Methods of assessing mental function, ${ }^{11}$ drug taking, ${ }^{12}$ urinary incontinence, ${ }^{13}$ falls ${ }^{14}$ eye disease, ${ }^{15}$ and anaemia ${ }^{16}$ have been described previously. Blood pressure was measured with a standard mercury sphygmomanometer after the subject had been lying for five minutes. Measurements were then repeated with the subject standing after one minute and three minutes. Systolic pressure was recorded at the first sound and diastolic at the disappearance of sound. Postural hypotension was defined as a fall of $20 \mathrm{~mm}$ of mercury or more in systolic pressure on standing. Functional ability was assessed in activities of daily living by the nurse and medical investigators. Blood was taken at the initial medical interview, and erythrocyte sedimentation rate (ESR) was measured by the Westergren method. In the prediction of mortality ESR was treated as a binomial variable using $20 \mathrm{~mm} / \mathrm{h}$ as the upper limit of normal on the evidence of the study data and subsequent studies. ${ }^{17}$

In the follow up the death of any subject participating in the study was recorded with the date and death certificate causes of death. All those surviving were reviewed in their own homes.

A life table method of analysis was used to determine factors predicting mortality. Survival in months from the date first seen was used as the dependent variable. The log rank test was used to determine which variables significantly related to survival. The prevalence of a number of the conditions examined, in particular, dementia, urinary incontinence, falls, and high systolic blood pressure, increased with age. Therefore the effect of each of these variables controlling for age was tested using a Cox's regression. ${ }^{18}$

For each of these significant predictors of survival, survival curves have been produced. After controlling for age, variables found significant formed the independent variables for a proportional

Table 1 Sample followed during study period

\begin{tabular}{lcc}
\hline Age group (years) & Alive & Dead \\
\hline $65-69$ & 13 & 2 \\
$70-74$ & 25 & 5 \\
$75-79$ & 50 & 22 \\
$80-84$ & 129 & 77 \\
$85-89$ & 72 & 74 \\
$90+$ & 19 & 47 \\
Total & 308 & 227 \\
\hline
\end{tabular}

hazards general linear model procedure. The SAS package was used for this analysis.

\section{Results}

Of the 559 subjects who completed the initial assessment 535 were followed until death or the follow up examination. The age distribution of those subjects who were followed for the full study period or died during the study are shown in table 1 . Twenty four subjects left the area or were lost to follow up.

There was no significant difference between the survival of men and women. All subsequent analyses were done for both sexes combined.

Those variables which did predict mortality in the log rank analysis are shown in table 2 , and those which did not reach significance are also listed for comparison. The variables which entered as predictors of mortality after controlling for age are identified by an asterisk.

The survival curves for all subjects, for each of these variables, are shown in figures 1 to 6 . The survival curves show the subjects who survived during the follow up period as a proportion of the total number of subjects who could have reached each age during the study period.

The variables which predicted mortality were then entered in the Cox's proportional hazards general linear model to determine the best fit for all significant variables. Those variables which best predicted mortality are shown in table 3.

Certain conditions were not present in a sufficient number of subjects to enter as significant predictors of mortality in the whole sample. However, when present, they were associated with a marked increase in mortality. Of the 12 subjects who had urinary catheters at the initial examination, 11 had died by final follow up. Of 19 subjects with anaemia in the initial examination only four survived for follow up.

Table 2 Results of survival analyses

\begin{tabular}{ll}
\hline Factors predicting mortality & Factors not predicting mortality \\
\hline Log rank test & Log rank test \\
Mental function* & Diastolic pressure \\
Functional capacity* & Postural hypotension \\
Urinary incontinence* & Senile macular degeneration \\
Prescribed drugs* & Cataract \\
Pulse pressure & Glaucoma \\
Erythrocyte sedimentation & Optimum vision \\
rate (ESR)* & \\
Systolic pressure & \\
Cardiovascular drugs & \\
Pattern falls* & \\
Age & \\
\hline *Significant controlling for age &
\end{tabular}

*Significant controlling for age 
Table 3 Factors best predicting mortality using the proportional hazards general linear model

\begin{tabular}{lrl}
\hline Variable & \multicolumn{1}{l}{ Beta } & $p$ \\
\hline Age & 0.044 & 0.003 \\
Functional capacity & 0.243 & 0.010 \\
Mental function & -0.339 & 0.008 \\
Urinary incontinence & 0.259 & 0.002 \\
Prescribed drugs & 0.134 & 0.010 \\
ESR & 0.013 & 0.006 \\
\hline
\end{tabular}

$R=0 \cdot 228$

Functional disability survival curves

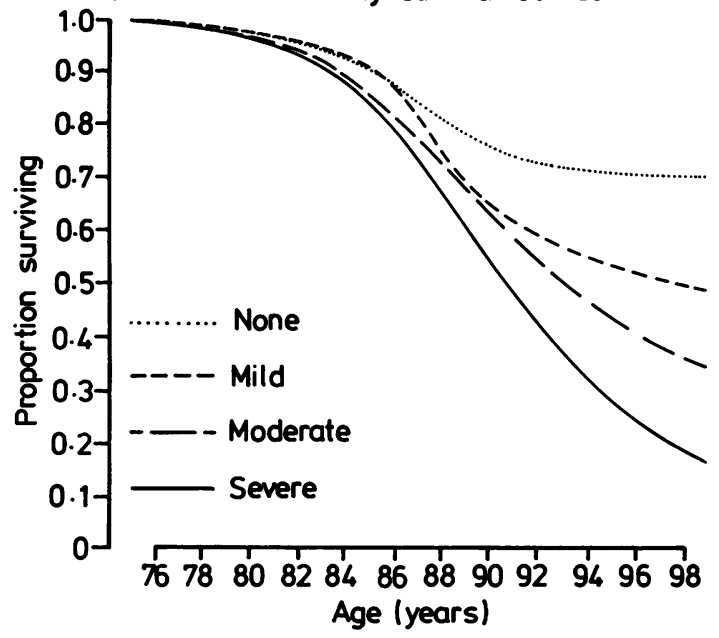

Mental function survival curves

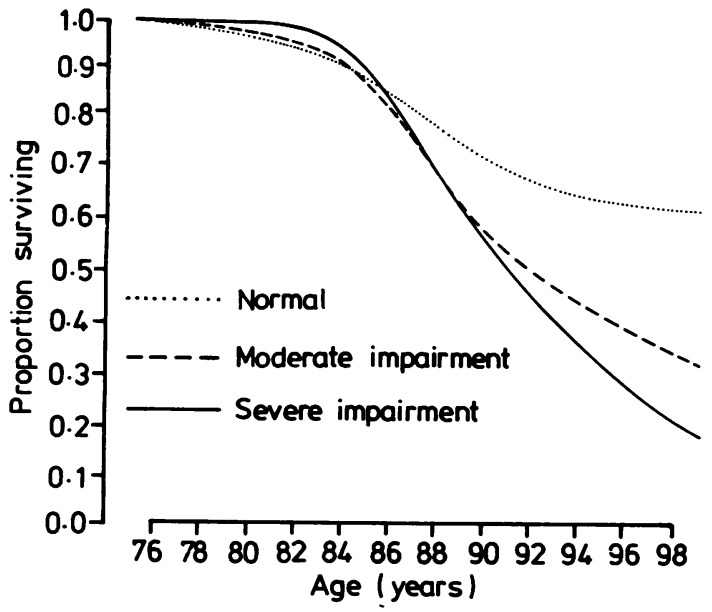

Of the 31 subjects who had faecal incontinence at the time of initial examination only three survived for follow up. The increase in mortality associated with the presence of urinary catheter, with anaemia, or with faecal incontinence occurred irrespective of the age of the subject.

\section{Discussion}

The sample of elderly people that we have studied
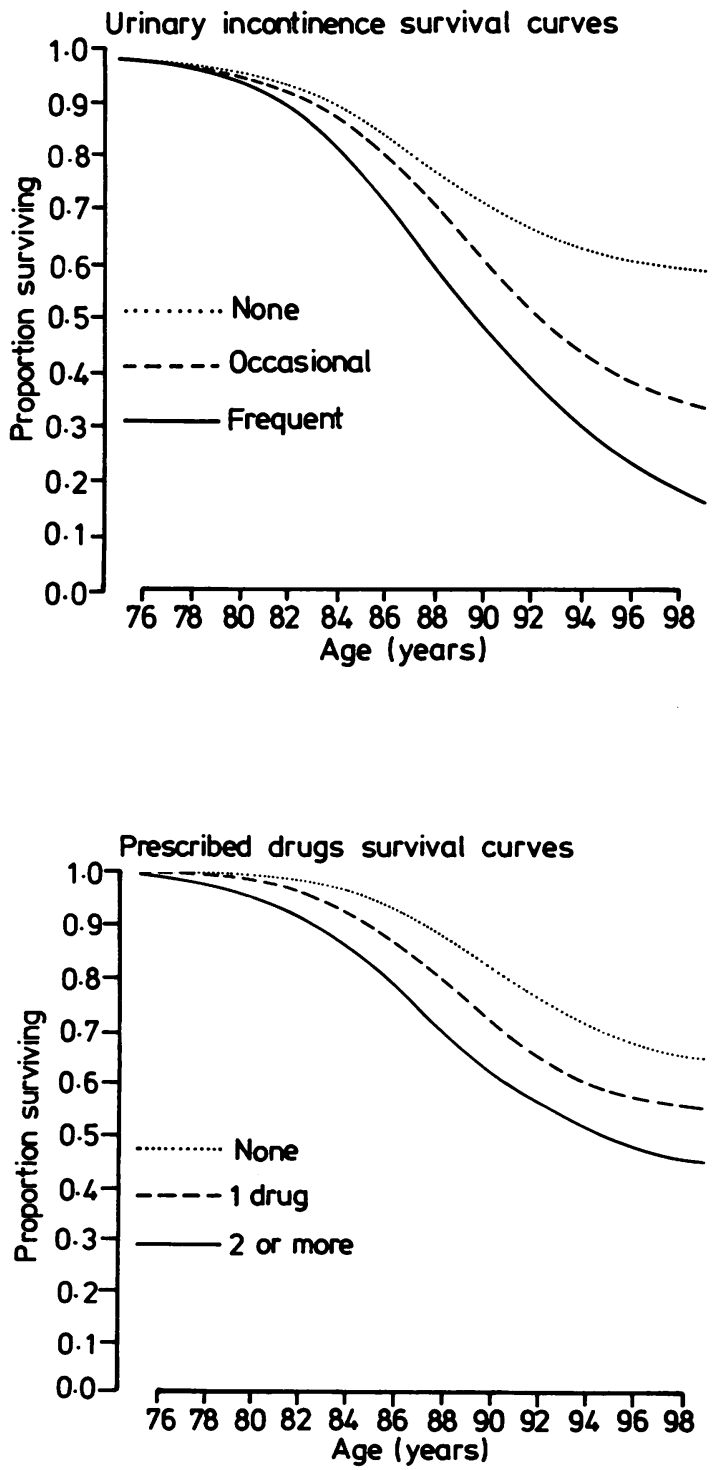

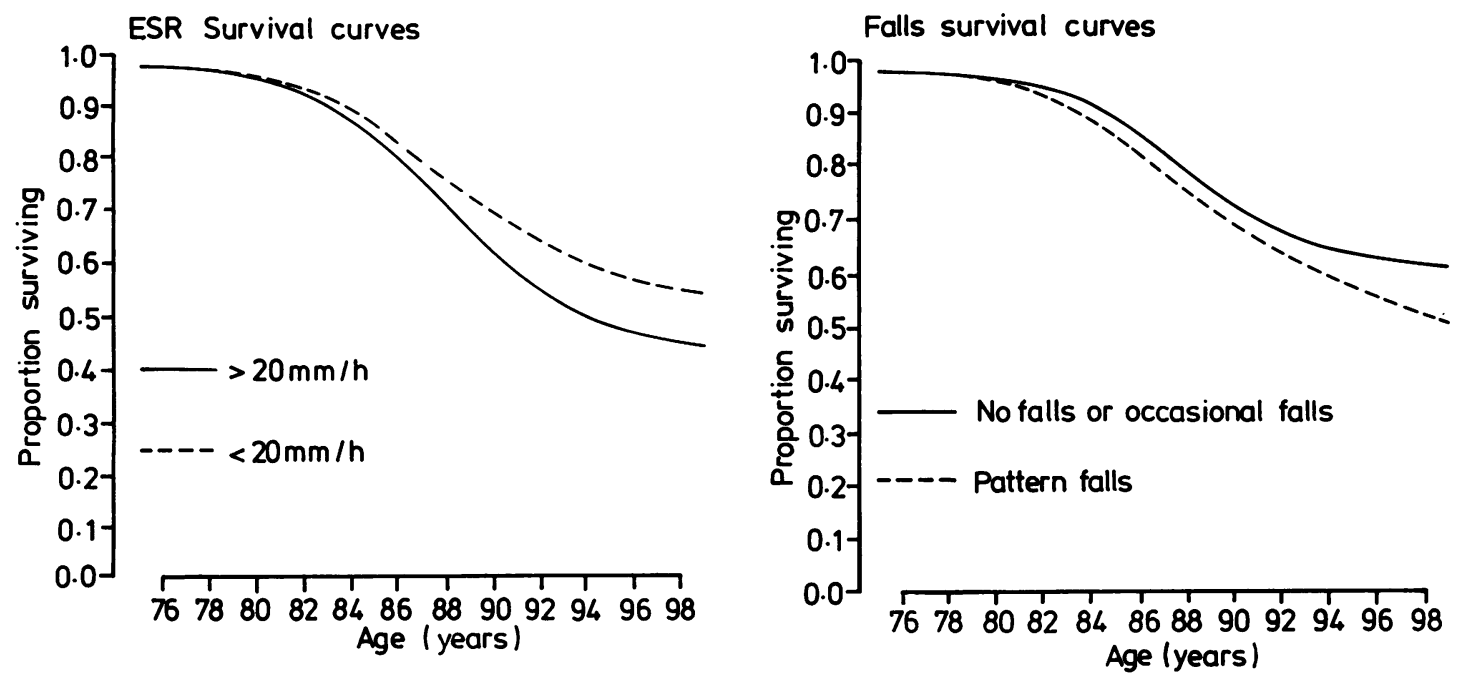

Figs 1 to 6 Survival curves for conditions predicting mortality. The survival curves show the subjects who survived during the follow up period as a proportion of the total number of subjects who could have reached each age during the study period.

was representative of a total population of the elderly including both those in the community and in institutional care. The initial refusal rate of $5 \cdot 1 \%$ and the $4 \cdot 1 \%$ of subjects lost to follow up were too small to bias the results. However, the number of subjects in the 65-74 years age group was small. This was partly due to subjects moving to a higher age group between the time of sampling and the initial examination. The results are therefore more applicable to people 75 years and over than to those 65 to 74 years.

The factors that we found most important in predicting mortality were those which indicated established disease. Impaired mental function, as defined in this study, was an indicator of established dementia. ${ }^{11}$ Dementia has previously been shown to be associated with lowered survival ${ }^{19}{ }^{20}$ although the length of survival of those affected may be increasing. ${ }^{21}$ People with senile dementia, Alzheimer's type, or multi-infarct dementia may have decreased survival because of the direct effects of the illness itself, because of increased risk of accidents, and because physicians may be less active in treating coincidental life threatening illness.

Other factors, such as urinary incontinence and falls, which we have shown to be associated with a decreased time of survival, are more likely to be markers of underlying frailty or illness than direct causes of mortality in their own right. Bacteriuria has been associated with increased mortality in men. ${ }^{22} \mathrm{It}$ is probable that the bacteriuria is a marker of increased risk of infection and impaired immunityo rather than that the urine infection itself causes death. Elderly people who experience falls ${ }^{23}$ or who have impaired mobility ${ }^{9}$ have previously been shown to have diminished survival. Few deaths, however, result from accidents and fractures, and the falls are a marker of frailty.

Raised blood pressure, which is so important in younger age groups as a risk factor for mortality, did not enter as a predictor in the present study. Previous studies of elderly people have also shown that the association of raised blood pressure with death ${ }^{24}{ }^{25}$ and stroke ${ }^{26}{ }^{27}$ is much less clear in the elderly than in younger subjects. Elderly people are a survival population, and people with significant hypertension have an increased risk of death before reaching old age. Frail elderly people may have lower blood pressures than those who are fit, ${ }^{28}$ and low blood pressure has been associated with increased mortality in the aged. ${ }^{29}$ However, when we separated those with low blood pressure we found no increase in mortality in this group. The justification for treating raised blood pressure in elderly people is not so clear as in younger age groups and requires further study. Other risk factors for vascular disease in younger life, such as smoking, obesity, and raised blood sugar, may also have different significance in old age groups. 
Branch and $\mathrm{Jette}^{30}$ examined the association of physical activity, cigarette smoking, hours of sleep, alcohol consumption, and the number of meals on five year mortality in a sample of subjects 65 years and over. In the multivariate analysis none of these factors related to survival in men, and in women only never having smoked cigarettes was significantly related to lower mortality. Care must be taken in extrapolating results and treatment recommendations from young to old age groups. In old age, disease may be established, and treatment of the "causes" of disease is no longer of benefit. ${ }^{31}$

Impaired mental function and functional disability were both associated with increased mortality. These results have importance in the planning of institutional requirements. Impaired intellectual function is an important reason for institutional care. ${ }^{11}$ The decreased survival of those with impaired intellectual function may lead to shorter lengths of time in care. Functional disability has previously been shown to be an important predictor of mortality in institutional groups ${ }^{12}$ and in the community. ${ }^{4}$ If people with high levels of functional ability are admitted to institutional care, the institutional requirements will increase for two reasons: not only will more people be admitted initially, but they will survive longer and the subsequent "turnover" of residents will be considerably less.

In old age the predictors of mortality are markers of established disease. This has implications in preventive health measures, in the treatment of certain conditions such as hypertension, and in the planning of services for the elderly.

This study was supported by research grants from the War Pensions Medical Research Trust, New Zealand. Dr Reinken and Ms Diep are indebted to Dr R Barker, Director-General of Health, for his permission to publish.

Requests for reprints to: A John Campbell, Professor of Geriatric Medicine, Department of Medicine, University of Otago, Dunedin, New Zealand.

\section{References}

${ }^{1}$ Booth T, Phillips D, Barritt A, Berry S, Martin DN, Melotte C. Patterns of mortality in homes for the elderly. Age and Ageing 1983; 12: 240-4.

${ }^{2}$ Donaldson LJ, Jagger C. Survival and functional capacity: three year follow up of an elderly population in hospitals and homes. J Epidemiol Comm health 1983; 37: 175-9.

${ }^{3} \mathrm{McCoy}$ JL. Antecedents of mortality among the old-age assistance population. Soc Sec Bull 1979; 42: 3-15.

${ }^{4}$ Warren MD, Knight $R$. Mortality in relation to the functional capacities of people with disabilities living at home. J Epidemiol Comm Health 1982; 36: 220-3.
${ }^{5}$ Thompson EG, Eastwood MR. Survivorship and senile dementia. Age and Ageing 1981; 10: 29-32.

${ }^{6}$ Mossey JM, Shapiro E. Self rated health: A predictor of mortality among the elderly. AJPH 1982; 72: 800-8.

${ }^{7}$ Hodkinson HM, Exton-Smith AN. Factors predicting mortality in the elderly in the community. Age and Ageing 1976; 5: 110-5.

${ }^{8}$ Milne JS, Lauder IJ. Factors associated with mortality in older people. Age and Ageing 1978; 7: 129-36.

${ }^{9}$ Abramson JH, Gofin R, Peritz E. Risk markers for mortality among elderly men-A community study in Jerusalen. J Chron Dis 1982; 35: 565-72.

${ }^{10}$ Salmond GC. The accommodation and service needs of the elderly. Dept of Health (NZ) Special Report 1976; 46.

"Campbell AJ, McCosh LM, Reinken J, Allan BC. Dementia in old.age and the need for services. Age and Ageing 1983; 12: 11-6.

${ }^{12}$ Campbell AJ, McCosh LM, Reinken J. Drugs taken by a population based sample of subjects 65 years and over in New Zealand. NZ Med J 1983; 96: 378-80.

${ }^{13}$ Campbell AJ, Reinken J. McCosh LM. Urinary incontinence in the elderly: Prevalence and prognosis. Age and Ageing. In press.

${ }^{14}$ Campbell AJ, Reinken J, Allan BC, Martinez GS. Falls in old age: a study of frequency and related clinical factors. Age and Ageing 1981; 10: 264-70.

${ }^{15}$ Martinez GS, Campbell AJ, Reinken J, Allan BC. Prevalence of ocular diseases in a population study of subjects 65 years old and older. Am J Opthalmol 1982; 94: 181-9.

${ }^{16}$ Campbell AJ, Murphy C. Reinken J, Allan BC. Anaemia in old age: a study of prevalence and causes. NZ Med J 1981, 94: 209-11.

${ }^{17}$ Griffiths RA, Good WR, Watson NP, O'Donnell HF, Fell PJ, Shakespeare JM. normal erythrocyte sedimentation rate in the elderly. Br Med J 1984; 289: 724-5.

${ }^{18}$ Cox DR. Regression models and life tables. $J R$ Stat Soc 1972; 34: 187-220.

${ }^{19}$ Kay DWK, Bergmann K, Foster EM, McKechnie A, Roth M. Mental illness and hospital usage in the elderly. A random sample followed up. Comp Psych 970; 11: 26-35.

${ }^{20}$ Maule MM, Milne JS, Williamson J. Mental illness and physical health in older people. Age and Ageing 1984; 13: 349-56.

${ }^{21}$ Gruenberg EM. Epidemiology of senile dementia. In Schoenberg BS, ed. Advances in neurology. New York: Raven Press 1978: 19: 437-57.

${ }^{22}$ Dontas AS, Kasviki-Charvati P, Papanayiotou PC, Marketos SG. Bacteriura and survival in old age. $N$ Engl J Med 1981; 304: 939-43.

${ }^{23}$ Wild D, Nayak USC, Isaacs B. How dangerous are falls in old people at home? $\mathrm{Br}$ Med J 1981; 282: 266-8.

${ }^{24}$ Miall WE, Brennan PJ. In Onesti G, Kim KE, eds Hypertension in the young and old. New York: Grune and Stratton 1981, 277-82.

${ }^{25}$ Anderson F, Cowan NR, Survival of healthy older people. Br J Prev Soc Med 1976; 30: 231-2.

${ }^{26}$ Grimley Evans J, Prudham D, Wandless I. In the ageing brain-neurological and mental disturbances. Barbagella-Sangiori G, Exton-Smith AN, eds. New York: Plenum Publishing Group 1980; 113-26.

${ }^{27}$ Milne JS. A longitudinal study of blood pressure and stroke in older people. J Clin Exp Gerontol 1981; 3: 135-9.

${ }^{28}$ Hulme A, Murdoch C, Ritchie RT, Chosh UK, MacLennan WJ. Low blood pressure in old women receiving long term care. J Clin Exp Gerontol 1981; 3: 353-5. 
${ }^{29}$ Rajala S, Harvisto M. Heikinheimo, Mattila K. Blood pressure and mortality in the very old. Lancet 1983; 2: 520.

${ }^{30}$ Branch LG, Jette AM. Personal health practices and mortality among the elderly. AJPH 1984; 74: 1126-9.
${ }^{31}$ Grimley Evans J. Prevention of age-associated loss of autonomy: Epidemiological approaches. $J$ Chron Dis 1984; 37: 353-63. 